\title{
Cacing yang Ditularkan Melalui Tanah pada Anak Sekolah Dasar di Sekitar Klinik Sanitasi di Lombok Timur, Nusa Tenggara Barat
}

\author{
Sri S Margono*, Widodo Sukardi **, Is Suhariah Ismid*, S Alisab N Abidin*
}

\begin{abstract}
Klinik sanitasi di suatu puskesmas di Lombok Timur, Nusa Tenggara Barat, memberikan pelayanan pasien yang menderita penyakit dan yang mempunyai masalah sanitasi lingkungan. Adanya klinik sanitasi tersebut tidak dapat mencegah tingginya prevalensi infeksi cacing yang ditularkan melalui tanah pada dua sekolah yang berjarak dekat dengan puskesmas tersebut. Di antara 175 dan 113 anak masing-masing di sekolah dasar A dan B. ditemukan infeksi cacing Ascaris lumbricoides dan Trichuris trichiura berturut-turut sebanyak 96,6\% dan 79,4\% di sekolah A, sementara di sekolah B 73,5\% dan 69,0\%. Untuk mengetahui intensitas infeksi dilakukan hitung telur per gram (TPG) yang mendapatkan angka-angka 3884 dan 2102 untuk Askariasis berturut-turut di sekolah A dan B, sementara untuk Trikhuriasis angka TPG adalah 436 dan 205. Sampel tanah yang dikumpulkan di sekitar rumah memperlihatkan telur Akcaris positif pada $8(17,0 \%)$ di antara 47 rumah murid sekolah A dan 11 (22,9\%) di antara 48 rumah murid sekolah B. Kuesioner yang dibagikan kepada keluarga yang tinggal di 95 rumah tersebut memperlihatkan bahwa fasilitas untuk mendukung kesehatan lingkungan tidak memadai seperti kakus, tempat sampah, dan air bersih. Tercatat adanya higiene perorangan yang bertaraf rendah.
\end{abstract}

Kata kunci: Lombok, klinik sanitasi, Askaris, Trikhuris, sekolah dasar

P ada tahun 1995 suatu klinik sanitasi diadakan di puskesmas di Wanasaba, Lombok Timur, Nusa Tenggara Barat. Klinik sanitasi tersebut harus memberikan pelayanan pada pasien yang mengunjungi puskesmas tersebut yang menderita penyakit dan mempunyai masalah-masalah kesehatan lingkungan. Pelayanan ditekankan pada pencegahan dan pengobatan penyakit dalam hubungannya dengan

Bagian Parasitologi FKUI, Jakarta (Prof. DR. Dr. Sri Margono, Dr. Is Suhariah Ismid, S Alisah N Abidin) dan Ditjen P2M PLP Departemen Kesehatan dan Penyehatan Lingkungan Pemukiman dan Kesejahteraan Rakyat Republik Indonesia (Dr. Widodo Sukardi).

Alamat korespondensi: Prof. DR. Dr. Sri Margono.

Bagian Parasitologi FKUI, Jl. Salemba 6, Jakarta 10430.

Tel. 021-3102135. Fax. 021-3914607/3923216.

E-mail: parasitologi@hotmail.com. sanitasi lingkungan. Bila diperlukan, seorang petugas kesehatan akan mengunjungi rumah pasien untuk mengadakan perbaikan lingkungan. Setelah pendirian klinik sanitasi di Wanasaba, beberapa klinik sanitasi lain juga didirikan di Propinsi Nusa Tenggara Barat, Jawa Timur, Sulawesi Tenggara, Sulawesi Selatan, Sumatera Selatan, dan Kalimantan Selatan.

Fokus sanitasi klinik bukan pada infeksi cacing yang ditularkan melalui tanah (soil transmitted helminths = $\mathrm{S}-\mathrm{TH}$ ), sehingga tidak ada data mengenai kelompok cacing ini. Untuk mendapat data tersebut telah dilakukan penelitian pada dua sekolah dasar di sekitar suatu puskesmas yang mempunyai klinik sanitasi. Selanjutnya tanah di sekitar sejumlah rumah telah diperiksa terhadap telur Ascaris lumbricoides untuk menentukan adanya kontaminasi dengan tinja. Kondisi rumah-rumah tersebut juga dievaluasi. 


\section{Bahan dan Cara Penelitian}

Penelitian ini dilakukan di Lombok Timur, Nusa Tenggara Barat. Pada bulan November 1999, sebanyak 288 sampel tinja dikumpulkan dari dua sekolah dasar di daerah, yang mempunyai klinik sanitasi di puskesmas. Sampel tinja yang terdiri dari 175 dan 113 berturutturut dari murid-murid di Sekolah Aikmel (A) dan Sekolah Banjarsari (B) dikirim ke Laboratorium Kesehatan Propinsi. Pemeriksaan sampel tinja dilakukan memakai metode Kato-Katz. Tehnik Harada-Mori yang dimodifikasi dipakai untuk mendeteksi infeksi cacing tambang pada survei pertama. ${ }^{2}$ Pirantel pamoat diberikan oleh petugas Departemen Kesehatan sebagai berikut satu dosis tunggal pirantel pamoat $10 \mathrm{mg}$ per $\mathrm{kg}$ berat badan dibagikan kepada murid-murid yang telur pada sampel tinjanya memperlihatkan telur positif pada bulan Januari 2000. Pemeriksaan kedua terhadap sampel tinja dilakukan pada bulan April 2000.

Sebagai tambahan, sampel tanah dikumpulkan dan diperiksa (Kagei, 1983), dari keempat sisi 47 dan 48 rumah anak-anak sekolah berturut-turut dari sekolah A dan sekolah B pada awal penelitian. Hubungan antara higiene kondidi ke-95 rumah dan sanitasi lingkungan di tiap daerah dievaluasi, menurut standar Departemen Kesehatan. Fasilitas kesehatan lingkungan, kondisi fisis rumah dan perilaku penghuninya dalam hubungan dengan kesehatan lingkungan diamati dan dicatat.

\section{Hasil}

Prevalensi total infeksi cacing yang ditularkan melalui tanah S-TH (soil transmitted hilmeth) pada 175 dan 113 sampel adalah 97,1 dan $88,5 \%$ berturut-turut di sekolah A dan B. Prevalensi askariasis adalah 96,6 dan 73,5\% untuk sekolah A dan B berturut-turut, sementara untuk trikhuriasis 79,4 dan 69,0\%. Tidak ditemukan satupun kasus infeksi cacing tambang. Hitung telur per gram EPG (egg counts per gram) adalah 3884 dan 2102 untuk askariasis berturut-turut di Sekolah A dan B, sementara untuk EPG trikhuriasis adalah 436 dan 205 (Tabel 1,3).

Jumlah sampel tinja yang dikumpulkan pada bulan April 2000 adalah 112 dan 103 berturut-turut di Sekolah A dan B. Di antara sampel-sampel ini sebanyak 87,5 dan 79,6\% terinfeksi oleh S-TH berturut-turut di Sekolah A dan B. Prevalensi askariasis adalah 55,4 dan $29,1 \%$ sementara untuk trikhuriasis 83,0 dan $79,6 \%$ berturut-turut di sekolah A dan B. Hitung telur per gram (EPG) untuk askariasis adalah 140 dan 256, sementara untuk trikhuriasis 672 dan 245 berturutturut di sekolah A dan B (Tabel 2, 3). Setelah mendapat pengobatan pirantel pamoat di sekolah A di antara 105 kasus dengan infeksi Askaris, 49 (46,7\%) menjadi negatif, sementara di antara 84 kasus di sekolah B, 59 $(70,2 \%)$ menjadi negatif (Tabel 4). Tujuh dan duapuluh enam anak dengan sampel tinja negatif untuk telur Askaris, berturut-turut di sekolah A dan

Tabel 1. Prevalensi infeksi cacing yang ditularkan melalui tanah (S-TH) pada anak-anak sekolah dasar sebelum pengobatan

\begin{tabular}{ccccc}
\hline \multirow{2}{*}{ Sekolah } & Jumlah sampel tinja & \multicolumn{2}{c}{ Prevalens (\%) } \\
\cline { 3 - 4 } & & Askaris & Trikhuris & S-TH \\
\hline A & 175 & 96,6 & 79,4 & 97,1 \\
B & 113 & 73,5 & 69,0 & 88,5 \\
\hline
\end{tabular}

Tabel 2. Prevalensi infeksi cacing yang ditularkan oleh tanah (S-TH) pada anak-anak sekolah dasar 3 bulan setelah pengobatan dengan pirantel pamoat (PP)

\begin{tabular}{ccccc}
\hline \multirow{2}{*}{ Sekolah } & \multirow{2}{*}{ Jumlah sampel tinja } & \multicolumn{2}{c}{ Prevalens (\%) } \\
\cline { 3 - 5 } & & Askaris & Trikhuris & S-TH \\
\hline \multirow{2}{*}{ A } & 112 & 55,4 & 83,0 & 87,5 \\
B & 103 & 29,1 & 79,6 & 79,6 \\
\hline
\end{tabular}

Catatan: PP tidak mempunyai pengaruh terhadap trikhuriasis 
Tabel 3. Intesitas infeksi sebelum dan 3 bulan setelah pengobatan dengan pirantel pamoat (PP)

\begin{tabular}{ccccc}
\hline \multirow{2}{*}{ Sekolah } & \multicolumn{2}{c}{ EPG } \\
\cline { 2 - 5 } & \multicolumn{2}{c}{ Askaris } & Sebelum & Srikhuris \\
\cline { 2 - 5 } & Sebelum & Sesudah & 436 & 672 \\
A & 3884 & 140 & 205 & 245 \\
B & 2102 & 256 & & \\
\hline
\end{tabular}

Catatan: EPG = hitung telur per gram tinja

PP tidak mempunyai pengaruh terhadap trikhuriasis

Tabel 4. Jumlah kasus dengan askariasis yang berkonversi menjadi negatif 3 bulan setelah pengobatan di sekolah Aikmel dan Banjarsari

\begin{tabular}{cccc}
\hline Sekolah & Sebelum pengobatan & Berkonversi \\
\cline { 2 - 4 } & Jumlah sampel & Jumlah & $\%$ \\
\hline Aikmel & 105 & 49 & 46,7 \\
Banjarsari & 84 & 59 & 70,2 \\
\hline
\end{tabular}

Tabel 5. Jumlah kasus negatif yang berkonversi menjadi telur Askaris positif 3 bulan setelah pemeriksaan tinja pertama di sekolah Aikmel dan Banjarsari

\begin{tabular}{cccc}
\hline \multirow{2}{*}{ Sekolah } & Sebelum pengobatan & \multicolumn{2}{c}{ Berkonversi } \\
\cline { 2 - 4 } & $\mathrm{n}$ & $\mathrm{N}$ & $\%$ \\
\hline Aikmel & 7 & 5 & 71,4 \\
Banjarsari & 26 & 11 & 42,3 \\
\hline
\end{tabular}

B, lima $(71,4 \%)$ dan sebelas $(42,3 \%)$ menjadi positif pada pemeriksaan kedua (Tabel 5).

Di lingkungan sekitar, $8(17,0 \%)$ dari 47 rumah murid sekolah A dan 11 (22,9\%) di antara 48 rumah murid sekolah B ditemukan positif mengandung telur Askaris (Tabel 6). Hasil dari sampel tanah bersama dengan tinja didapatkan dari 26 rumah. Di antara 26 sekitar rumah 15 positif Askaris, 12 positif telur Askaris untuk sampel tanah maupun tinja, dua positif telur Askaris di tanah, walaupun begitu sampel tinjanya positif telur Trikhuris, sementara satu sampel tanah positif Askaris tapi sampel tinja negatif terhadap telur S-TH.

Kuesioner dibagikan kepada responden, yaitu orang tua murid sekolah pengamatan dilakukan terhadap fasilitas kesehatan lingkungan dan data tentang perilaku keluarga yang tinggal di 95 rumah (47 rumah murid sekolah A dan 48 dari sekolah B) dicatat. Hasil yang berhubungan dengan persoalan tentang cacing S-TH dilaporkan dalam makalah ini.

Di antara responden 53,7\% memakai air ledeng yang tersedia untuk masyarakat dan 15,2\% memakai air dari sumur terbuka dan hanya 45,3\% mempunyai fasilitas kakus. Hanya 17,9\% mempunyai tempat sampah dan banyak di antara mereka mengumpulkan sampah di lubang di halaman rumah (16,8\%). Walaupun kebanyakan rumah berlantai semen

Tabel 6. Telur Askaris pada sampel tanah dari sekitar rumahrumah anak-anak sekolah A dan B

\begin{tabular}{ccc}
\hline Rumah & $\begin{array}{c}\text { Jumlah } \\
\text { rumah }\end{array}$ & $\begin{array}{c}\text { Jumlah rumah } \\
\text { yang positif }(\%)\end{array}$ \\
\hline A & 47 & $8(17,0)$ \\
B & 48 & $11(22,9)$ \\
\hline
\end{tabular}


Tabel 7. Fasilitas untuk mendukung kesehatan lingkungan dari 95 responden (orangtua murid di sekolah A dan B)

\begin{tabular}{lcc}
\hline Fasilitas & Jumlah & $\%$ \\
\hline Kakus & 43 & 45,3 \\
Air ledeng untuk masyarakat & 51 & 53,7 \\
Tempat sampah & 17 & 17,9 \\
Lantai: & & \\
$\quad$ Semen & 78 & 82,1 \\
$\quad$ Tanah & 24 & 25,3 \\
$\quad$ Becek & 27 & 28,4 \\
\hline
\end{tabular}

$(82,1 \%)$, duapuluhlima persen rumah berlantai tanah (sebagian atau seluruhnya) dan $28,4 \%$ rumah tampak basah (Tabel 7).

Tentang higiene perorangan, 97,9\% mengaku mandi teratur, 96,8\% dengan sabun, 74,7\% menggosok gigi dan $73,7 \%$ memotong kuku secara teratur. Hanya $58,9 \%$ memasak air untuk pemakaian sehari-hari dan hanya $26,3 \%$ membuang sampah ke dalam tempat sampah. Di antara rumah-rumah itu 76,8\% mempunyai jendela, walaupun begitu hanya $43,2 \%$ membuka jendela secara teratur. Fasilitas kakus digunakan oleh 50,5\% responden, 48,4\% membersihkan kakus dan $55,8 \%$ mempunyai fasilitas air bersih. Kebanyakan responden $(97,9 \%)$ mengaku membersihkan peralatan makan mereka sebelum dipakai.

\section{Pembahasan}

Ditemukan prevalensi yang sangat tinggi untuk infeksi Askaris dan Trikhuris di sekolah A sebagaimana juga sekolah B, walaupun ada suatu pelayanan sanitasi di puskesmas yang memberikan konsultasi dan melakukan kunjungan rumah untuk kasus diare dan penyakit lain, dalam hubungan dengan kesehatan lingkungan. Di dekat sekolah A, jamban dan tempat air dengan pipa tambahan dibuat dan dijual dengan harga terjangkau. Di sekitar pusat sanitasi pendidikan kesehatan, terutama untuk sanitasi diberikan kepada masyarakat, walaupun begitu, nyata bahwa perhatian terhadap infeksi S-TH tidak memadai.

Secara umum intensitas infeksi cacing rendah, walaupun begitu aspek lain yang juga menentukan tingkat penularan adalah jumlah sampel dengan telur fertil, yang tidak dievaluasi dalam penelitian ini.

Sekolah B terletak lebih jauh dari Puskesmas dan klinik sanitasi, walaupun begitu tingkat reinfeksi dan infeksi baru jauh lebih rendah daripada di sekolah A
(Tabel 4,5). Perkumpulan orangtua-guru (POMG) di sekolah $\mathrm{B}$ ternyata berfungsi jauh lebih baik daripada di sekolah A. POMG di sekolah B lebih banyak ikut serta dalam kegiatan sekolah, termasuk kegiatan kesehatan. Di sekolah B yang disebut "dokter kecil" dari kelas yang lebih tinggi memberikan pelajaranpelajaran khusus mengenai topik kesehatan. Mungkin pengetahuan tentang kesehatan meningkat, walaupun begitu perilaku sehat yang baik masih kurang, tercermin dari prevalensi infeksi S-TH yang tinggi. Walaupun kedua sekolah secara fisik kondisinya baik, sekolah B lebih bersih.

Ditemukan bahwa prevalensi Askaris di antara anakanak di sekolah A adalah 96,6: 17,0 = 5,7 kali lebih banyak daripada jumlah rumah yang positif telur Askaris dan di sekolah B 73,5: 22,9 = 3,2 kali lebih banyak daripada rumah yang positif. Tehnik laboratorium dalam mencari telur Askaris di tanah lebih rumit dan sulit, sehingga pemeriksaan sampel tinja semata-mata, lebih praktis. Walaupun begitu, dalam evaluasi penggunaan jamban, pemeriksaan sampel tanah di sekitar rumah harus dipertimbangkan (Ismid et al, 1983).

Empatbelas anak dari limabelas rumah yang positif ternyata positif telur Askaris atau Trikhuris (2 anak), karena itu dapat dianggap bahwa 93,3\% daerah sekitar rumah-rumah itu terkontaminasi oleh anak-anak yang tinggal di rumah tersebut. Pada penelitian terdahulu, terlihat bahwa anak-anak sekolah dan balita kebanyakan terlibat buang air besar sembarangan di sekitar rumah mereka; sedangkan orang dewasa tidak memberi andil dalam polusi tanah di sekitar rumah. (Ismid et al, 1983).

Sebagai perbandingan dengan penelitian ini $(17,0$ dan 22,9\%) lebih banyak rumah dengan lingkungan yang positif telur Askaris ditemukan di Duren Sawit, Jakarta Timur yaitu $18(37,5 \%)$ di antara 48 halaman (Margono et al, 1989). Rampen (1986) menyebutkan $36,9 \%$ positif di Balekambang dan Cawang, yang juga daerah perifer di Jakarta Timur. Di daerah pedesaan seperti Serpong, Jawa Barat dan Sawahlunto, Sumatra Barat, berturut-turut $40 \%$ dan $57,7 \%$ ditemukan positif telur Askaris (Rukmono et al, 1977).

Air bersih hanya tersedia untuk 55,8\% dan hanya $58,9 \%$ di antara mereka biasa memasak air untuk minum. Didapatkan 45,3\% responden mempunyai fasilitas kakus, yang kurang lebih sesuai dengan fakta bahwa 50.5\% memakai kakus dan 48,4\% mempunyai kebiasaan membersihkan kakus. Telur cacing yang ditularkan lewat tanah dapat berkembang menjadi 
stadium infektif di lantai tanah, sehingga penularan dapat terjadi di dalam beberapa rumah responden. Di antara responden hanya $17,9 \%$ mempunyai tempat sampah atau tempat khusus untuk sampah dan hanya $26,3 \%$ membuang sampah mereka di tempat yang tersedia, berarti kebanyakan responden tampaknya tidak banyak peduli mengotori lingkungan dengan sampah.

Walaupun mandi dan memakai sabun merupakan kebiasaan dari kebanyakan responden, hanya kira-kira $70 \%$ menggosok gigi dan memotong kuku mereka secara teratur.

\section{Kesimpulan}

Konsultasi, diikuti dengan kunjungan rumah, sebagai suatu pelayanan tambahan oleh puskesmas, tidak mempunyai pengaruh terhadap prevalensi infeksi S-TH, yang sangat tinggi di dua sekolah dasar. Karena itu, pelayanan kesehatan yang berbeda harus lebih diintegrasikan dan lebih intensif diterapkan dalam rangka menurunkan prevalensi penyakit yang ditularkan secara oral seperti infeksi Askaris dan Trikhuris.

Sekolah A terletak lebih dekat dengan unit kesehatan lokal, tingkat reinfeksi dan infeksi baru untuk askariasis jauh lebih tinggi daripada anak-anak di sekolah B. Fenomena ini mungkin disebabkan oleh penanganan yang lebih baik dari PMOG dalam usaha meningkatkan kesehatan anak sekolah.

Tingkat kontaminasi di sekitar rumah ditemukan jauh lebih rendah daripada prevalensi infeksi Askaris pada murid sekolah A dan B. Pemeriksaan sampel tinja saja, sebagai indikator tingkat kontaminasi tanah lebih praktis daripada memeriksa sampel tanah.

Empatbelas anak (93,3\%), tinggal di 15 rumah dengan lingkungan positif telur Askaris, positif terhadap telur S-TH; oleh karena itu dapat diasumsikan bahwa daerah sekitar rumah terkontaminasi oleh anak-anak tersebut.

Fasilitas untuk mendukung kesehatan lingkungan tidak memadai seperti kakus, sampah dan fasilitas air bersih, yang juga sesuai dengan data higiene perorangan. Lingkungan dan kebiasaan responden, menunjang berkembangnya cacing S-TH dan mungkin mikroorganisme lain yang ditularkan secara oral.

\section{Ucapan terima kasih}

Kerjasama dengan petugas-petugas kesehatan setempat sangat dihargai. Terimakasih kami pada Bp. Mudjiharto, SKM, MM dan Bp. Fauzi Suherman, SKM dari Sub Direktorat Perumahan dan Sanitasi Lingkungan, Direktorat Jendral Pencegahan Penyakit Menular dan Sanitasi Lingkungan, Departemen Kesehatan, Indonesia yang membantu kami sebelum dan selama penelitian ini.

\section{Daftar Pustaka}

1. Ismid, I.S., Margono, S.S., Anggarini, S., Mahfudin, H., Rasad, R., Rasidi, R., dan Rukmono, B. The effect of mass treatment in different target groups on the dispersion of Ascaris eggs in the soil. Dalam: Collected Papers on the Control of Soil-transmitted Helminthiases, Vol.II. eds. Yokogawa, M.et al., APCO, Tokyo, 1983. h. 231-7.

2. Kagei, N. Techniques for the measurement of enviromental pollution by infective stage of soil-transmitted helmiths. Dalam: Collected Papers on the Control of Soiltransmitted Helmithiases, Vol.II.eds. Yokogawa,M. et al., APCO, Tokyo, 1983. h. 27-46.

3. Kosin,E., Timbul, L.T. dan Saroso, J.S. A simple culture method for nematode larvae. Madj. Kedokt.Indon 1973; 23: 7-10.

4. Margono,S.S., Ismid, I.S. dan Rukmono, B. (1989): Effect of control of soil-transmitted helminth infections in a suburban area in Jakarta, Indonesia. Dalam: Collected Papers on the Control of Soil-transmitted Helminthiases, Vol.IV. Yokogawa, M., et al., penyunting APCO, Tokyo, 1989. h. 95-104.

5. Rampen, A.S.L. Contamination of soil with Ascaris lumbricoides eggs in Bale Kambang and Cawang, Jakarta in different socio-economic communities. Thesis Bagian Pantiologi FKUI, 1986.

6. Rukmono,B., Ismid, I.S., Indriyono, Roesin, R., Suzuki, N. dan Hara, T. Soil pollution with Ascaris lumbricoides in Sawahlunto and Serpong. Dalam Collected Papers on the Control of Soil-transmitted Helminthiases, Vol.I. eds. Yokogawa, M., et al., APCO, Tokyo, 1977. h. 137-40. 